\title{
COMPORTAMENTO DE PREDAÇÃO DE PODISUS NIGRISPINUS (DALLAS, 1851) (HEMIPTERA: PENTATOMIDAE) EM FUNÇÃO DA DISPONIBILIDADE DE ALIMENTO
}

\section{R.R. Coelho, J.M. de Araujo Júnior, J.B. Torres}

Universidade Federal Rural de Pernambuco, Departamento de Agronomia-Entomologia, Av. Dom Manoel de Medeiros, s/nº, CEP 52171-900, Recife, PE, Brasil. E-mail: coelho.rr@gmail.com

\section{RESUMO}

Predadores com digestão extra-oral devem considerar vários fatores para atacar uma presa baseado na sua necessidade nutricional e no investimento para a sua manipulação. Este estudo investigou o comportamento de escolha entre uma fonte de umidade e uma presa pelo percevejo predador Podisus nigrispinus (Dallas) (Hemiptera: Pentatomidae) e ganho de peso dependendo de sua escolha. Predadores adultos, após $48 \mathrm{~h}$ sem alimentação, foram submetidos a três tipos de escolha: (i) água e pré-pupa de Alabama argillacea (Hübner, 1823) (Lepidoptera: Noctuidae), (ii) planta hospedeira (algodoeiro) e lagartas de A. argillacea (iii) e cada fonte de alimento individualmente. $P$. nigrispinus exibiu escolha similar entre alimentar-se da presa ou de água e mostrou preferência por plantas em comparação à presa. Quando sem chance de escolha, os predadores preferiram atacar a presa e exibiram similar escolha em alimentar-se ou não de água ou planta. Observou-se que o comportamento de predação de $P$. nigrispinus foi influenciado pela disponibilidade de uma fonte de umidade. Os predadores, apesar de possuir maior tempo de alimentação sobre a presa, apresentaram ganho de peso em todas as fontes de alimento com ingestão significante de água e seiva de planta. Tais resultados caracterizam a importância da presença da água no comportamento de predação de $P$. nigrispinus e que a sua disponibilidade deve ser considerada em estudos de comportamento de predação com este e/ou outros predadores com digestão extra-oral.

PALAVRAS-CHAVE: Asopinae, comportamento de predação, digestão extra-oral, percevejos predadores.

\section{ABSTRACT}

PPREDATORY BEHAVIOR OF PODISUS NIGRISPINUS (DALLAS, 1851) (HEMIPTERA: PENTATOMIDAE) AS AFUNCTIONOFFOODRESOURCE AVAILABILITY. Predators with extraoral digestion may consider several factors to attack a prey item based not only on the nutritional value but also on the energy expended in prey handling (capture, digestion and ingestion of liquefied content). The predatory stinkbug may require a large amount of water to produce saliva and enzymes used to digest prey tissues and, hence, exhibit behavior related to the water source. Thus, this study investigated the behavioral choice of the predator between a moisture source (water and plant) and a prey item and weight gain by the predatory stinkbug Podisus nigrispinus (Dallas) (Hemiptera: Pentatomidae). Predator adults had free choice to feed between water and the pre-pupa of Alabama argillacea (Hübner, 1823) (Lepidoptera: Noctuidae) (i), between the host plant (cotton) and larvae of $A$. argillacea (ii), or on each of these food sources individually (iii). Although starved for $48 \mathrm{~h}, P$. nigrispinus exhibited a similar choice between feeding either on water or on prey, and preferred to feed on plants compared to prey when having access to prey and cotton plants simultaneously. Under the non-choice test, predators chose to feed on the prey, and showed a similar choice to feed or not on the water and plant. Thus, the predator P. nigrispinus exhibited feeding behavior driven by the availability of the moisture source. Despite the greater time of feeding on prey, predators gained weight in all food items indicating significant ingestion of food material. Therefore, these results characterize the role of the moisture source on P. nigrispinus predatory behavior, indicating it as one factor that should be considered when studying predation rate with this and other predators with extra-oral digestion.

KEY WORDS: Asopinae, extra-oral digestion, predatory behavior, predatory stinkbug. 


\section{INTRODUÇÃO}

O comportamento de ataque e manipulação das presas por predadores com digestão extra-oral sugere que esses levam em consideração, na seleção do alimento, não somente a sua potencialidade em retorno nutricional mas, também, o investimento na sua manipulação. A manipulação da presa por tais predadores envolve o ataque, injeção de toxinas para digestão dos tecidos e posterior ingestão do conteúdoliquefeito para recuperação máxima do seu investimento. Este grupo de predadores (percevejos, aranhas, larvas de neurópteros etc.) requer disponibilidade de umidade para a produção de saliva contendoenzimas proteolíticas utilizadas na digestão dos tecidos de suas presas e redução da viscosidade para facilitar a sua ingestão (COHEN, 1998). Segundo POLLARD (1989), o aumento da viscosidade do conteúdo digerido da presa dificulta o aproveitamento total dos seus tecidos por predadores de digestão extra-oral. A zoofitofagia em percevejos predadores está relacionada à obtenção de umidade, o que favorece o metabolismo do inseto e o comportamento de predação (GILLESPIE;MCGREGOR, 2000) afetando, possivelmente, a seleção do alimento. A zoofitofagia é caracterizada pelo fato de insetos carnívoros se alimentarem também de material vegetal (produtos de plantas - seiva, pólene “"honeydew") (JERVIS;KIDD, 1996). Os predadores zoofitófagos, além da obtenção de umidade, podem se alimentar de seiva de plantas para complementar sua dieta em períodos de escassez de presas (COlL; GueRshon, 2002).

Percevejos zoofitófagos como Podisus nigrispinus (Dallas, 1851) (Hemiptera: Pentatomidae) têm digestão extra-oral e possuem mecanismos de adaptação no aparelho bucal e no complexo enzimático digestivo que os tornam aptos a exercerem, ocasionalmente, a fitofagia (COHEN, 1996; Oliveira et al., 2006). P. nigrispius é comumente encontrado em vários ecossistemas (Torres et al.,2006) e tem se tornado um modelo para estudos sobre fitofagia em predadores. Os resultados indicam melhorias nas características biológicas como menor duração ninfal, maior sobrevivência ninfal, maior longevidade e maior fecundidade de adultos (ZANUNCIO et al., 1993; OLIVEIRA et al., 2002; Evangelista JUNior et al., 2003). Isto pode ser explicado pelo fato de que predadores zoofitófagos, além da umidade, devem adquirir nutrientes quando se alimentam de plantas. Apesar de alimentarem ocasionalmente das plantas, especialmente daquelas hospedeiras de suas presas, este comportamento não é prejudicial às plantas. Até o momento, podemos dizer que a ausência de enzimas como pectinase, celulase e outras que são responsáveis pela digestão da parede celular dos tecidos vegetais no complexo salivar de percevejos zoofitófagos (COHEN, 1996; Hori, 2000; Azevedoetal., 2007) é a principal hipótese para a ausência de injúrias causadas as plantas hospedeiras. Além disso, ninfas e adultos de Podisus não são gregários, portanto, a alimentação não é concentrada em uma parte específica da planta o que reduz as chances de injúrias mecânicas.

Estudos de predação, usualmente através de resposta funcional, impõem aos predadores condições de escassez de presas e umidade, por períodos de 24 a $48 \mathrm{~h}$, anteriores as observações para equilibrar a saciação dos indivíduos teste e estimular maior movimentação e taxa de ataque (ToRres et al., 2002). Entretanto, a taxa de predação em percevejos predadores pode ser influenciada pela obtenção ou não de umidade (GILLESPIE; MCGREGOR, 2000), e predadores de digestão extra-oral como $P$. nigrispinus podem exibir comportamento de procura pela fonte de umidade (planta ou água livre como orvalho, chuva, irrigação) alternado ao comportamento de ataque à presa. Desta forma é importante a compreensão do comportamento desses predadores zoofitófagos em selecionar uma presa ou alimentar-se de plantas, visto que a zoofitofagia traz benefícios para eles (Evangelista Junior et al., 2003), mas também pode afetar a taxa de predação(GILLESPIE;MCGREGOR, 2000). Neste contexto, o objetivo do presente trabalho foi estudar o comportamento de P. nigrispinus em relação à escolha entre alimentar-se de uma fonte de umidade (água ou seiva da planta) ou depresa[Alabamaargillacea (Hübner, 1823)] e avaliar o tempo e o ganho de peso em função de sua alimentação.

\section{MATERIALEMÉTODOS}

Adultos de P. nigrispinus. Adultos do percevejo predador, P. nigrispinus, utilizados nos experimentos foram oriundos da colônia mantida no Laboratório de Controle Biológico da Universidade Federal Rural de Pernambuco(UFRPE). A criação foi realizada seguindo a metodologia descrita em TORRES et al. (2006), sob temperatura de $25 \pm 1^{\circ} \mathrm{C}$ e fotofase de $12 \mathrm{~h}$. Ninfas de segundo instar de P. nigrispinus foram separadas em gaiolas de acrílico e o alimento, pupas de Tenebrio molitor L. (Coleoptera: Tenebrionidae), foi oferecido em abundância durante toda a fase ninfal. Para os testes de comportamento foram utilizados adultos dos predadores que receberam água e pupas de $T$. molitor em abundância nos primeiros três dias de vida adulta e, posteriormente, foram mantidos sem alimentação por $48 \mathrm{~h}$.

Plantas de algodão. As plantas de algodão cultivar BRS 201 foram cultivadas em potes plásticos de $250 \mathrm{~mL}$ contendo mistura de solo e húmus na proporção de 4:1 e 8 a $10 \mathrm{~g}$ da mistura de adubo 
formulado NPK 4-14-8. O plantio foi realizado semanalmente para obtenção de plantas de, aproximadamente, 20 dias de idade durante todas as etapas do experimento.

Comportamento de escolha entre água e presa. Para este estudo foram utilizados 60 machos e 60 fêmeas da mesma idade de P. nigrispinus. A oferta de água ou presa para escolha do predador foi realizada em arena circular de acrílico de $14 \mathrm{~cm}$ de diâmetro e $3 \mathrm{~cm}$ de altura; no fundo externo da arena foram demarcados três pontos eqüidistantes que formaram um triângulo de $8 \mathrm{~cm}$ delado. Nointerior da arena, em um desses pontos de forma aleatória, foi colocada uma pré-pupa de $A$. argillacea, no outro ponto um recipiente plástico transparente contendo $1,5 \mathrm{~mL}$ de água destilada e, no terceiro ponto, um adulto do predador. As pré-pupas de A. argillacea foram pesadas imediatamente antes da oferta e o peso variou de 142,2 a 283,8 mg. Machos e fêmeas ao iniciar o sexto dia de idade e, após estarem $48 \mathrm{~h}$ sem alimentação, foram pesados e, imediatamente após, liberados no ponto marcado para recebê-los na arena.

Comportamento de escolha entre presa e planta hospedeira. Para este estudo foram utilizados 50 machos e 50 fêmeas de $P$. nigrispinus. Foram utilizadas caixas de acrílico transparente de 31 × 43 × $44 \mathrm{~cm}$ com aberturas laterais fechadas com tecido do tipo "organza" para a circulação de ar. Em cada gaiola foram colocadas duas plantas de algodão com 20 dias de idade (três a quatro folhas desenvolvidas). Uma dessas plantas foi infestada, $12 \mathrm{~h}$ antes da liberação do predador, com cinco a seis lagartas de terceiro instar de $A$. argillacea; neste período, a planta sem ataque e presença de lagartas foi mantida fora da gaiola. Findo este período, a planta de algodão, sem desfolha e lagartas, foi colocada no interior da gaiola, em posição oposta àquela infestada e mantidas cinco lagartas por planta. Machos e fêmeas de P. nigrispinus foram marcados com numerações sobre o tórax e pesados; em cada gaiola foram liberados cinco predadores, entre as duas plantas.

Avaliações. As observações foram contínuas atéo término de uma escolha ou por $14 \mathrm{~h}$. A avaliação procedeu com observação contínua até a primeira escolha para alimentação, duração da alimentação, ganho de peso do predador após a alimentação na planta ou presa e, caso a escolha fosse a pré-pupa de A. argillacea, esta também era pesada após o seu abandono. Oconsumo indireto da presa (pré-pupa de A. argillacea) pelo predador foi medido através da diferença entreo peso da presa antes eapós a predação. Oganhoem peso com a alimentação foi estimadopela diferença entre os pesos inicial do inseto e após sua alimentação. Além da escolha entre planta e presa, também foi avaliado a preferência do predador para alimentar-se de planta infestada (lagartas+desfolha) ou sem infestação. Caso não houvesse uma escolha neste período, aquele exemplar do predador (repetição) era descartado.

Controle do efeito isolado de cada componente de alimentação. Para estudar o comportamento de escolha ou não de água, presa ou planta de algodão quandoestes eram oferecidosisoladamente. Estecomportamento foi investigado com 170 fêmeas de $P$. nigrispinus, distribuídas em três tratamentos: 1. água (60 fêmeas); 2. presa (50 fêmeas) e3. planta de algodão (60 fêmeas).

Nesta etapa, as avaliações foram feitas quantificando otempoqueosinsetos passaram sealimentandoeopeso adquirido durante a alimentação.

Análise estatística. Os resultados de freqüência de escolha foram analisados através do Proc Freq e interpretados pelo teste do qui-quadrado para uma proporção 50:50 caso não houvesse escolha. O tempo de alimentação e peso adquirido foram submetidos à análise de variância pelo Proc GLM; os dados do tempo de alimentação foram transformados em log $(x+1)$ para atender os pré-requisitos de normalidade (Kolmogorov D: normal test) e homogeneidade de variância (Bartlett's test). Todas as análises foram conduzidas utilizando o programa estatístico SAS / STAT (2000).

\section{RESULTADOS}

Comportamento de escolha entre água e presa. A escolha de $P$. nigrispinus entre água e presa não diferiu estatisticamente tanto para machos $\left(\chi^{2}=\right.$ $0,3968 ; \mathrm{P}=0,5287)$, quanto para as fêmeas $\left(\chi^{2}=2,40\right.$; $\mathrm{P}=0,1213$ ) (Fig. 1), mesmo estando os predadores por $48 \mathrm{~h}$ sem alimentação em presa eágua. Entretanto, o tempo de alimentação foi diferente estatisticamente $(\mathrm{P}<0,0001)$ entre água e presa tanto para machos $\left(\mathrm{F}_{1,61}=95,26\right)$ quanto para fêmeas $(\mathrm{F} 1,58=$ 256,08); este tempo foi de 61,1 e 410,1 minutos para machos e, 46,2 e 545,8 minutos para fêmeas, respectivamente(Fig. 2A).

O peso adquirido após a alimentação diferiu estatisticamente tanto para os machos $\left(\mathrm{F}_{1,61}=9,64 ; \mathrm{P}\right.$ $=0,0029)$ como para as fêmeas $\left(\mathrm{F}_{1,58}=32,93 ; \mathrm{P}<\right.$ $0,0001)$ e foi maior quando os predadores alimentaram-se de pré-pupa de $A$. argillacea. Oganho médio de peso dos machos de $P$. nigrispinus após a alimentação de água ou de presa foi de 9,1 e 13,4 mg e, para as fêmeas, foi de 9,8 e22,9 mg, respectivamente(Fig. 2B). O consumo de presa por P. nigrispinus, entre a primeira e a segunda escolha para alimentação, independente da alimentação prévia em água, foi semelhante para machos e fêmeas $\left(\mathrm{F}_{1,49}=0,11 ; \mathrm{P}=0,7449\right.$ e $\mathrm{F}_{1,57}=$ $0,11 ; \mathrm{P}=0,7382)$ e variou de 5 a $28,3 \mathrm{mge} 6,5$ e $47,6 \mathrm{mg}$, respectivamente. 

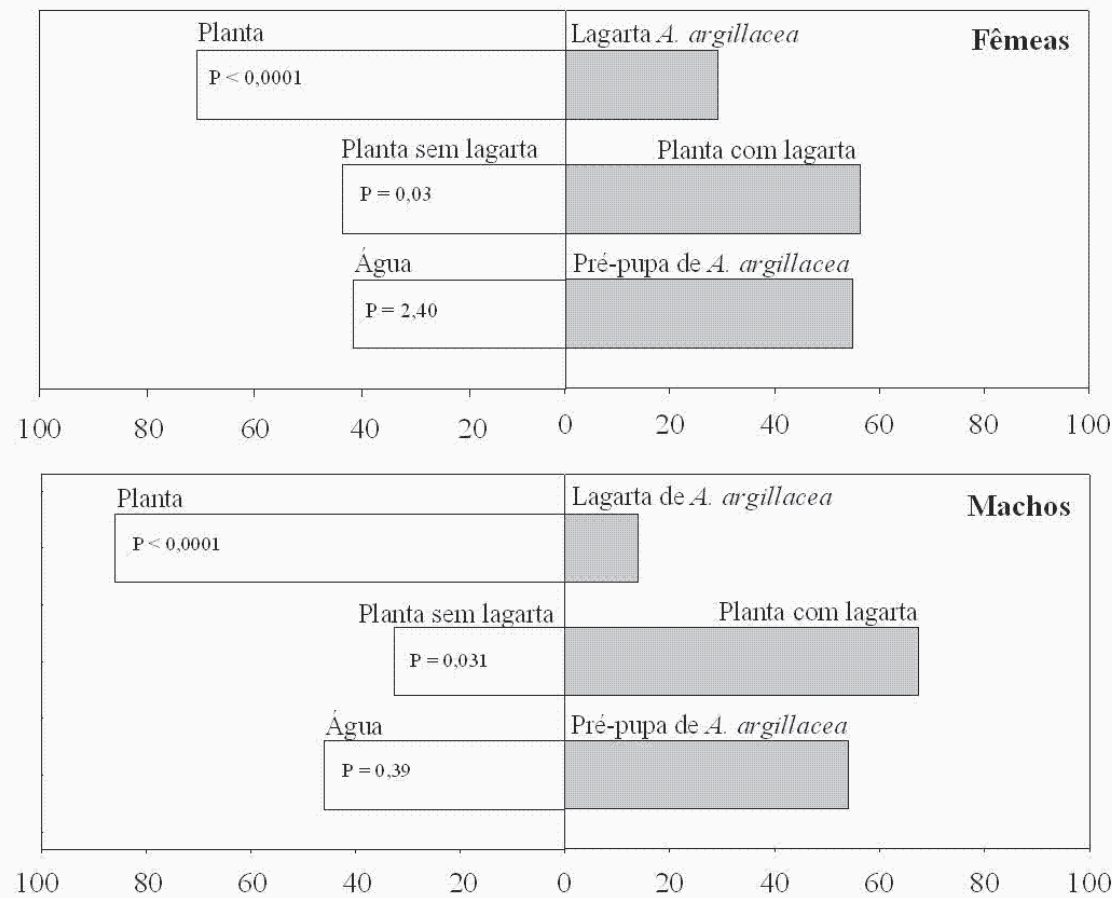

Porcentagem de escolha

Fig. 1 - Resultado de escolha entre as fontes de alimento (água, planta de algodão, pré-pupa ou lagarta de Alabama argillacea por machos e fêmeas de Podisus nigrispinus. Valores de P para o teste de $\chi^{2}$ contrastando as duas opções de escolha.

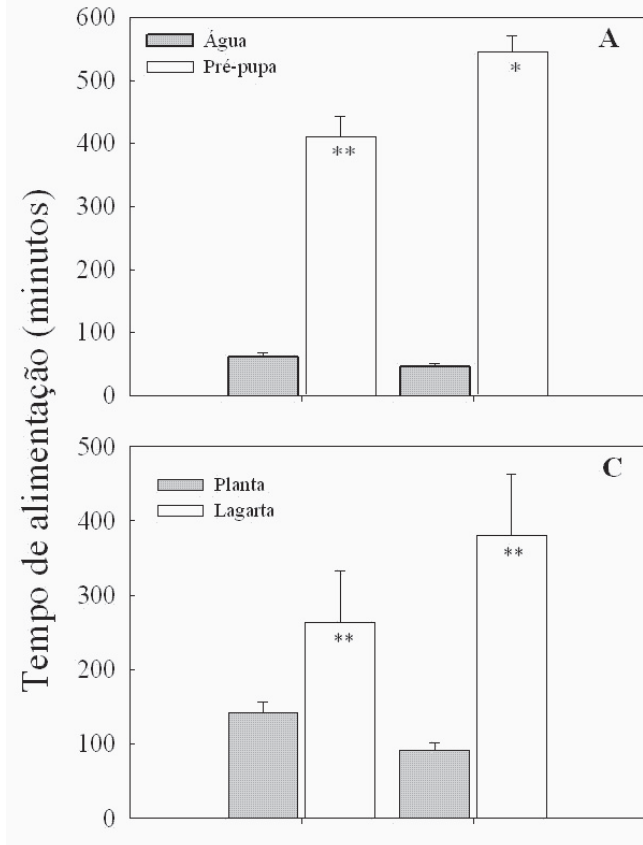

Machos Fêmeas

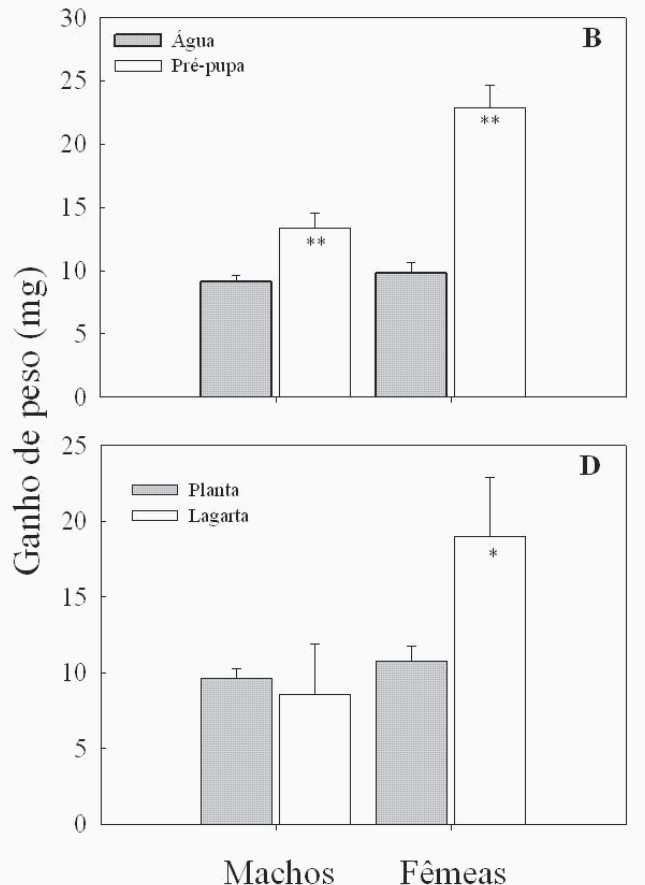

Fig. 2 - Tempo de alimentação (minutos) e ganho de peso (mg) de machos e fêmeas de Podisus nigrispinus alimentandose de água ou pré-pupa de Alabama argillacea (A e B) e de planta de algodão ou lagarta de A. argillacea (C e D), após realizada a escolha. Asteriscos nas colunas significam altamente significativo e significativo pelo teste F da ANOVA no nível de $1 \%\left({ }^{* *}\right)$ e $5 \%\left(^{*}\right)$ de probabilidade, respectivamente. 


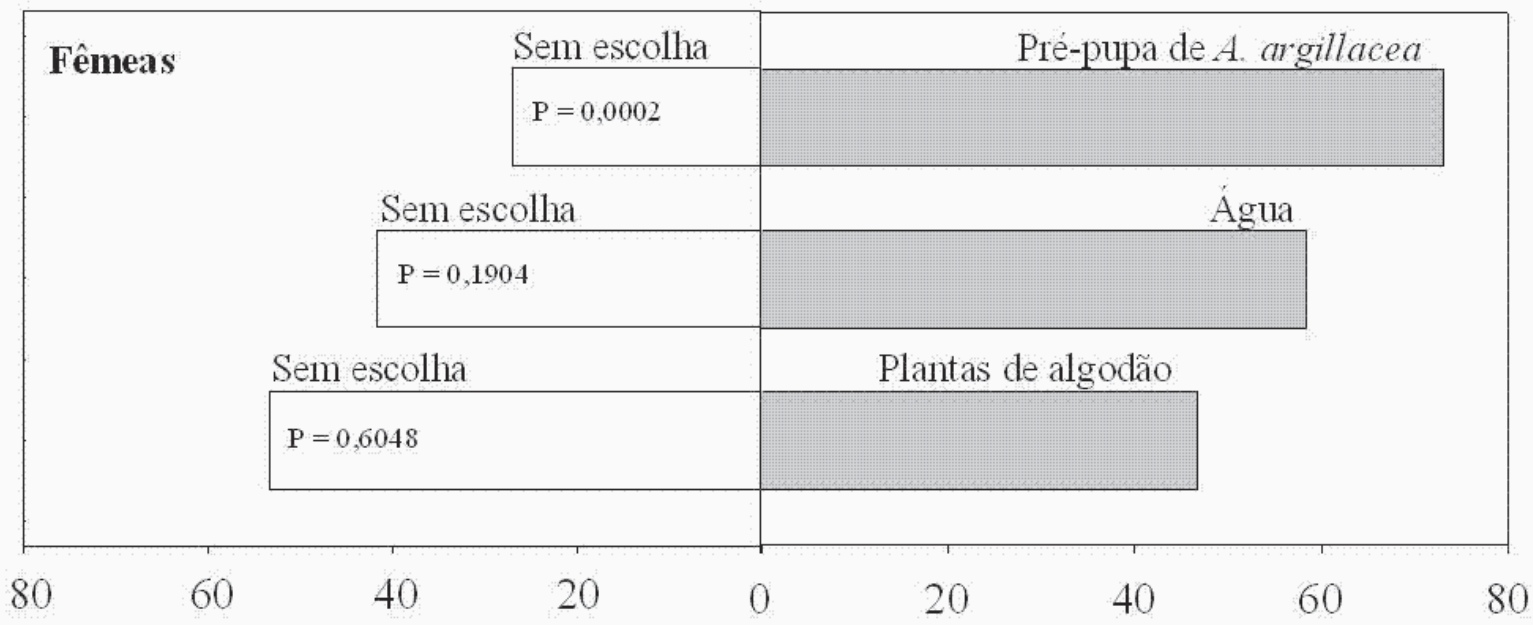

Porcentagem de escolha

Fig. 3 - Comportamento de escolha ou não de fêmeas de Podisus nigrispinus por fontes de alimento individualizadas (água, pré-pupa de Alabama argillacea e planta de algodão). Valores de P para o teste de $\chi^{2}$ contrastando escolha e não escolha.
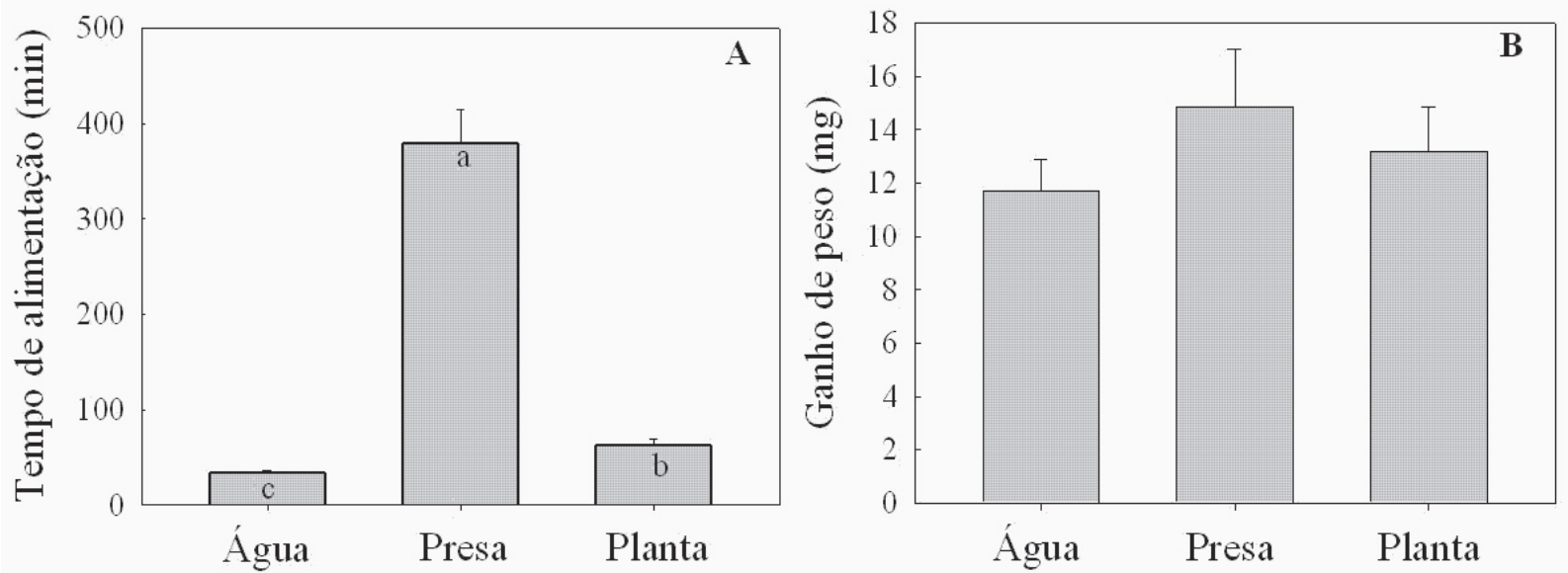

Fig. 4 - Tempo de alimentação (A) e ganho de peso (B) de fêmeas de Podisus nigrispinus alimentando-se de fontes de alimento individualizadas (água, pré-pupa de Alabama argillacea e planta de algodão).

Comportamento de escolha entre presa e planta hospedeira. Os predadores mostraram preferência para alimentarem-se de planta de algodão $(\mathrm{P}<0,05)$ em relação a lagartas de $A$. argillacea (Fig. 1). Além disso, ao escolher a planta para se alimentar, o predador apresentou uma preferência significativa $(\mathrm{P}<0,05)$ por plantas infestadas com $A$. argillacea em detrimento às plantas sem infestação (Fig. 1).

O tempo médio de alimentação na planta foi menor tanto para machos $\left(\mathrm{F}_{1.48}=7,84 ; \mathrm{P}=0,0073\right)$ quanto para fêmeas $\left(\mathrm{F}_{1,44}=19,19 ; \mathrm{P}<0,0001\right)$, em comparação à alimentação em lagartas de $A$. argillacea (Fig. 2C). Da mesma forma o peso adquirido na alimentação foi quase duas vezes maior quando as fêmeas alimentaram-se das lagartas em comparação às plantas (planta, $10,81 \mathrm{mg}$ versus lagarta, $18,97 \mathrm{mg})\left(\mathrm{F}_{1,44}=5,68 ; \mathrm{P}=\right.$ $0,0215)$ (Fig. 2D). Apesar da diferença no tempo de alimentação de machos, o ganho de peso durante sua alimentação em presa ou planta de algodão foi semelhante (presa, $\mathrm{F}_{1,48}=1,08 ; \mathrm{P}=0$,2502; planta, $\mathrm{F}_{1,44}=$ 2,18; $\mathrm{P}=0,1552$ ).

Controle do efeito isolado de cada componente de alimentação. Fêmeas de $P$. nigrispinus, quando tiveram acesso a fontes de umidade individualizada (água ou planta), exibiram resposta equilibrada por um período de $12 \mathrm{~h} ; 58,3 \%$ e 41,7\% das fêmeas não 
apresentaram preferência entre alimentar-se ou não de água $\left(\chi^{2}=1,71 ; \mathrm{P}=0,19\right)$ ou planta $\left(\chi^{2}=0,27 ; \mathrm{P}=\right.$ $0,60)$. Entretanto, $73 \%$ das fêmeas recebendo prépupas de $A$. argillacea responderam significativamente atacando e consumindo a presa $\left(\chi^{2}=13,42 ; \mathrm{P}=\right.$ 0,0002 ) (Fig.3). Além disso, o tempo médio dealimentação das fêmeas do predador foi maior na presa, diferindo do tempo gasto para alimentação em água e planta de algodão $\left(\mathrm{F}_{2,48}=70,82 ; \mathrm{P}<0,0001\right)$ (Fig. 4A) à semelhança do experimento anterior, sendo o menor tempodealimentaçãoobservadopara fêmeas alimentando-se de água. O peso adquirido pelas fêmeas de $P$. nigrispinus alimentando em água, planta ou prépupa de $A$. argillacea não diferiu estatisticamente entre as fontes de alimento $\left(\mathrm{F}_{2,48}=0,67 ; \mathrm{P}=0,5185\right.$ (Fig. 4B). Apesar da não diferença entre as fontes de alimento, o ganho de peso das fêmeas do predador aumentou em função do tempo de alimentação na água $(\mathrm{r}=0,61 ; \mathrm{P}=0,0207)$, na presa $(\mathrm{r}=0,64 ; \mathrm{P}=0,0007)$ ena planta de algodão $(r=0,79 ; P=0,0012)$ indicando o consumo do alimento em todas as fontes testadas.

\section{DISCUSSÃO}

Percevejos predadores podem adquirir umidade através de gotas deágua sobre as plantas oriundas de orvalho, chuva eirrigaçãoe através da seiva da planta hospedeira. A busca por umidade, seja de gotas sobre as plantas ou sugando ocasionalmente as plantas, também pode colocar P. nigrispinus em risco de contaminação por ingerir gotas das aplicações inseticidas na superfície das plantas e inseticidas sistêmicos presente na seiva da planta (TORRES; RUBERSON, 2004), além das demais formas de contato. Isto demonstra que a umidadeéum fator limitantena história de vida desses predadores.

A escolha semelhante entre água e presa pode indicar que a seleção inicial por presa ou água provavelmente ocorreu ao acaso e se houvesse direcionamento para escolha esta seria esperada ocorrer para a predação (pré-pupa de A. argillacea) por se tratar de um carnívoro. Os dois recursos oferecidos (água e presa) eram imóveis, "incapazes" de se defenderem do ataque e poderiam ser encontrados com a movimentação ao acaso do percevejo. A necessidade de umidade foi, ainda, reforçada pela preferência inicial de alimentação na planta em relação a lagartas de $A$. argillacea, apesar deestarem por $48 \mathrm{~h}$ sem alimentação em presa (Fig. 1). Isto vem provar que a fonte de umidade disponível interfere no comportamento de predação de P. nigrispinus, após este ficar período sem recursos de alimentação. A manutenção de percevejos predadores por 24 ou $48 \mathrm{~h}$ sem acesso ao alimento para igualar o status de saciação dos indivíduos a serem submetidos a teste de predação, como nos estudos de resposta funcional, deve ser reconsideradoeoferecer umidadea eles nesteperíodo. Esteestudo corrobora os relatos de GILLESPIE; McGREGOR (2000) e BOYDJUNIOR; ALVERSON (2004) sobre o efeito da umidadena predação de percevejos predadores; os resultados obtidos indicaram que $P$. nigrispinus utilizam fontes de umidade como água (gotas de orvalho, irrigação) ou seiva de plantas para obter sucesso de predação, mesmo sem alimentação e com presa disponível (Fig. 1).

A fonte de umidade irá certamente auxiliar na produção de saliva e síntese de enzimas além da umidade exigida no metabolismo normal do organismo. Além da escolha pela planta de algodão, também foi interessante a preferência por plantas infestadas com lagartas de $A$. argillacea, indicando que a seleção destes predadores pode ser guiada por dois fatores: a planta como fonte de alimento após período sem alimentação e a presença de presas na planta escolhida para posterior predação. A preferência por plantas de algodão infestadas pelas lagartas pode ser decorrente da vibração foliar causada pela alimentação das lagartas ou presença de resíduos fecais, odores liberados pela praga ou mesmo pela planta atacada (Seigler;Price 1976, Pfannestiel et al., 1995) e, também, pela injúria ocasionada nas plantas pelas lagartas durante o período de $12 \mathrm{~h}$ queantecedeu a liberação do predador. Embora questionável em relação a predadores generalistas, existem algumas evidências que voláteis de plantas emitidos, quando estas estão sob ataque de herbívoros, podem favorecer a atração de predadores (SABELIS et al., 2001); esta hipótese pode explicar a atratividade de $P$. nigrispinus por plantas de algodoeiro infestadas com $A$. argillacea.

Quando oferecidos individualmente água, presa e planta, as fêmeas do predador responderam significativamente para alimentação em presa e igualmente entre alimentar da água e planta (Fig. 3). Este resultado claramente indica que a necessidade de umidade altera o comportamento de predação de $P$. nigrispinus, pois, na presença de fontes de umidade (água e planta) mais presa, os predadores não apresentaram preferência significativa para se alimentar da presa e, de fato, maior preferência pela planta em comparação à presa (Fig. 1A-B). Além disso, a correlaçãoexistente entre o tempo dealimentaçãoe oganho depesocomprova que, duranteo período que oinseto está se alimentando, ele está ingerindo alimento. Segundo GILlesPie;McGregor (2000), existem três explicações funcionais para a alimentação de zoofitófagos em plantas: (1) a planta repõe componentes nutricionais quando há escassez de presa; (2) o material vegetal fornece nutrientes essenciais capazes de auxiliar o inseto na predação como, por exemplo, a água, que pode ser requerida para a digestão extraoral em hemípteros predadores, e (3) o tecido vegetal 
disponibiliza nutrientes essenciais não adquiridos pelo consumo de presas. Dessa forma, é importante compreender a complexidade da seleção do alimento por zoofitófagos. Por isso, énecessária a realização de novos estudos para compreender a complexidade da seleção de alimento por zoofitófagos e que visem a determinação deescolhas subseqüentes do predador entre planta e presa por períodos de observação superiores a $14 \mathrm{~h}$. Além disso, estudos de resposta funcional com percevejos predadores devem considerar a disponibilidade de umidade aos predadores nos períodos que antecede as observações para que ele, ao ser liberado sobre plantas com as pragas alvo, não direcione a alimentação para a planta em busca de umidade.

\section{CONCLUSÃO}

O comportamento de seleção do alimento por $P$. nigrispinus é influenciado pela disponibilidade da planta hospedeira da presa ou deágua livre, sugerindo que uma fonte de umidade para estes predadores com digestão extra-oral deva ser considerada em estudos de comportamento de alimentação, estudos com dieta e outros que envolvam predação.

\section{AGRADECIMENTOS}

AoCNPq, à CAPES pelas bolsas eà FACEPE(APQ0157-5.01/06) pelo aporte financeiro. Também, agradecemos a Robério C.S. Neves pela manutenção das criações de T. molitor e P. nigrispinus e Roberta L. dos Santos pela disponibilidade delagartas de A. argillacea.

\section{REFERÊNCIAS}

AZEVEDO, D.O.; ZANUNCIO, J.C.; ZANUNCIO JR, J.S.; MARTINS, G.F; MARQUES-SILVA, S.; SOSSAI, M.F.; SERRÃO, J.E. Biochemical and morphological aspects of salivary glands of the predator Brontocoris tabidus (Heteroptera: Pentatomidae). Brazilian Archives of Biology and Technology, v.50, n.3, p.469-477, 2007.

BOYD, D.W.; ALVERSON, D.R. Effects of temperature and water source on development of Deraeocoris nebulosus (Uhler) (Hemiptera: Miridae), a predaceous plant bug. Journal of Entomological Science, v.39, n.1, p.202-213, 2004.

COHEN, A.C. Plant feeding predatory Heteroptera: evolutionary and adaptacional aspects of trophic switching. In: Alomar, O.; WiedenManN, R.N. (Ed.). Zoophytophagous Heteroptera: Implications for life history and Integrated Pest Management. Lanham: Entomological Society of America, 1996. chap. 1, p.1-17.
COHEN, A.C. Solid-to-liquid feeding: the inside (s) story of extra-oral digestion in predaceous arthropoda. American Entomologist, v.44, Summer, p.103-115, 1998.

COLL, M.; GUERSHON, M. Omnivory in terrestrial arthropods: mixing plant and prey diets. Annual Review of Entomology, v.47, p.267-297, 2002.

EVANGELISTA JUNIOR, W.S.; GONDIM JR, M.G.C.; TORRES, J.B.; MARQUES, E.J. Efeito de plantas daninhas e do algodoeiro no desenvolvimento, reprodução e preferência para oviposição de Podisus nigrispinus (Dallas) (Heteroptera: Pentatomidae). Neotropical Entomology, v.32, n.4, p.677-684, 2003.

GILLESPIE D.R.; McGREGOR, R.R. The functions of plant feeding in the omnivorous predator Dicyphus hesperus: water places limits on predation. Ecological Entomology, v.25, n.4, p.380-386, 2000.

HORI, K. Possible causes of disease symptoms resulting from the feeding of phytophagous Heteroptera. In: SCHAEFER, C.W.; PANIZZI, A.R. (Ed.). Heteroptera of economic importance. Boca Raton: CRC Press, 2000. chap. 2, p.11-35.

JERVIS, M.A.; KIDD, N.A.C. Phytophagy., In: Insect Natural Enemies: practical approaches to their study and evaluation. London: Chapman \& Hall, 1996. p.375-394.

OLIVEIRA, J.E.M.; TORRES, J.B.; CARRANOMOREIRA, A.F.; BARROS, R. Efeito das plantas do algodoeiro e do tomateiro, como complemento alimentar, no desenvolvimento e na reprodução do predador Podisus nigrispinus (Dallas) (Heteroptera: Pentatomidae). Neotropical Entomology, v.31, n.1, p.101108, 2002.

OLIVEIRA, J.A.; OLIVEIRA, M.G.A.; GUEDES, R.N.C.; SOARES, M.J. Morphology and preliminary enzyme characterization of the salivary glands from the predatory bug Podisus nigrispinus (Heteroptera: Pentatomidae). Bulletin of Entomological Research, v.96, n.3, p.251-258, 2006.

PFANNESTIEL, R.S.; HUNT, R.E.; YEARGAN, K.V. Orientation of a hemipteran predator to vibrations produced by feeding caterpillars. Journal of Insect Behavior, v.8, n.1, p.1-9, 1995.

POLLARD, S.D. Constraints affecting partial prey consumption by a crab spider, Diaea sp. (Araneae: Thomisidae). Oecologia, v.81, n.3, p.392-396, 1989.

SABELIS, M.W.; JANSSEN, A.; KANT, M.R. The enemy of my enemy is my ally. Science, v.291, n.5511, p.21042105, 2001.

SAS INSTITUTE. 2000. User's guide, version 8.02, TS level 2MO. SAS Institute Inc., Cary, NC. 
SEIGLER, D.; PRICE, P.W. Secondary compounds in plants: primary functions. American Naturalist, v.110, n.971, p.101-105, 1976.

TORRES, J.B.; RUBERSON, J.R. Toxicity of thiamethoxam and imidacloprid to Podisus nigrispinus (Dallas) (Heteroptera: Pentatomidae) nymphs associated to aphid and whitefly control in cotton. Neotropical Entomology, v.33, n.1, p.99-106, 2004.

TORRES, J.B.; EVANGELISTA JUNIOR, W.S.; BARROS, R; GUEDES, R.N.C. Dispersal of Podisus nigrispinus (Het., Pentatomidae) nymphs preying on tomato leafminer: effect of predator release time, density and satiation level. Journal of Applied Entomology, v.126, n.6, p.326-332, 2002.
TORRES, J.B.; ZANUNCIO, J.C.; MOURA, M.A. The predatory stinkbug Podisus nigrispinus: biology, ecology and augmentative releases for lepidopteran larval control in Eucalyptus in Brazil. Biocontrol News and Information, v.27, n.3, p.1-15, 2006. Disponível: <http:/ / www. pestscience.com/reviews.asp\#bni2703> Acesso em: 11 jun. 2007.

ZANUNCIO, J.C.; FERREIRA, A.T.; GARCIA, J.F. Influence of feeding on Eucalyptus urophylla seedlings on the development of the predatory bug Podisus connexivus (Hemiptera: Pentatomidae). Mededelingen Faculteit Landbouwwetenschappen Rijksuniversiteit Gent, v.58, n.2, p.469-475, 1993.

Recebido em 30/11/07

Aceito em 10/11/08 